\title{
Street Soccer programme participation: Experiences of young people with psychosis
}

Philip Williams, Chris Lloyd, Robert King, Michael Paterson

Aims: This exploratory, qualitative, study aimed to identify why young people who had experienced psychosis consistently decided to attend the Street Soccer programme.

Method: Patients using the early psychosis tertiary mental health service who were regularly attending the Street Soccer programme at the time of data collection were invited to participate in this exploratory qualitative study. Out of eight people invited, six young people agreed to be participants. All participants engaged in a one-to-one, semi-structured interview, which was recorded, transcribed and analysed using thematic analysis to reveal key themes related to the research question.

Results: The key themes revealed from the thematic analysis included: needing to be encouraged to join the group; feeling welcomed and encouraged; gaining personal benefit (getting outside the house, getting fit, feeling less anxious) and increased desire to participate in new activities.

Conclusions: Participation in the group programme was not dependent on participants having established treatment goals to initially attend but rather on persistent encouragement to attend by a health worker. The participants continued to attend the Street Soccer programme due to the group culture, and the tangible benefits they perceived were a result of their attendance.

Philip Lee Williams is an Occupational Therapist and Team Leader of the Early Psychosis Service as part of the Gold Coast Hospital and Health

Service, Australia;

Chris Lloyd is an occupational therapist who currently works as a Principal Research Fellow between Griffith University and Gold Coast Hospital and Health Service, Australia;

Robert King is a Professor at the School Of Psychology And Counselling, The University of Queensland, Australia; Michael Paterson Michael is a Clinical Nurse in the Early

Psychosis Service as part of the Gold Coast Hospital and Health service, Australia.

Correspondence to: Philip Williams

E-mail: philip_lee_ williams@health.qld. gov.au

Key words: $\square$ Soccer $\square$ Early psychosis $\square$ Recovery $\square$ Group therapy

Submitted 30 July 2013, sent back for revisions 10 October 2013; accepted for publication following double-blind peer review 21 November 2013

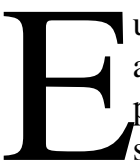
uropean football (soccer in Australia) is a genuinely global sport, which can be played at almost all levels of fitness and skill and understood by most people. As a group-based activity, soccer is highly adaptable and can be graded to suit the specific group scenario. This study's Street Soccer programme was designed to engage young, at-risk people, including those who experienced mental illness, drug addiction, and homelessness, in a weekly sporting activity.

Despite the weight of evidence supporting the benefits of physical activity and participation (Hodgson et al, 2011; Richardson et al, 2005), engaging and maintaining participation rates for people with mental illnesses in appropriate programmes is an ongoing challenge (Carless, 2007). Staff within a tertiary mental health service observed that people were consistently choosing to attend and continue attending the Street Soccer programme at higher rates than other group programmes on offer. At the time of this study, a range of groups were on offer, including artistic, social, life skills, other activity-based groups (surfing) as well as the Street Soccer programme.

To gain a rich understanding of this observed effect, the authors used an exploratory, qualitative methodology to design a research project. This design aimed to reveal why young people who had experienced psychosis consistently decided to attend the street soccer group and to explore participants' perspective of their experience of the group.

The benefits of physical activity for improving mental and physical health among those with a major mental illness are well known. Benefits of physical activity for people with mental illness include: reduced mental illness symptoms (Ellis et al, 2007); positive changes in physical functioning, mental health and vitality (Tessier et al, 2007); decreased risks associated with diabetes, improved physical functioning, less risk of developing cognitive impairment, and improved emotional wellbeing, mood state, and social support (Penedo and Dahn, 2005).

\section{Participants' perspectives}

Daumit et al (2005) reported that people with a mental illness are less physically active than the general population and more likely to walk as their sole form of physical activity. Saxena et al (2005) suggested that physical activity interventions should be used as a strategy in psychosocial rehabilitation. However, much less is understood about how to support people to participate in physical activity programmes than is known about the 
benefits of such interventions. Soundy et al (2007) identified that outpatients with a mental illness were ambivalent about becoming more active and received little or no support to do so.

A number of sporting programmes for people with serious mental illness have examined the effects of participation. For example: Carless and Douglas (2004) described a golf programme and reported a high attendance rate, enthusiasm for the sessions, social interaction after the game, and continued participation post programme; Crone (2007) reported that a walking programme played a significant part in the participants' quality of life through autonomy, achievement, purpose, and enjoyable, memorable experiences; Carless and Douglas (2008) reported that participants from various exercise activity groups benefited from receiving and at times from giving social support.

\section{Soccer and mental health}

A number of papers report the use of soccer for successfully engaging people with mental illnesses in a physical activity programme. Carter-Morris and Faulkner (2003) reported that participants with severe mental illness who attended a soccer project found that it: was very beneficial; offered the opportunity for social interactions within a normalising activity context; helped to challenge auditory hallucinations and delusional beliefs; but that medication side effects were the most significant barriers to participation. However, there was no in-depth review of the participants' reasons for initially choosing to attend the group. The 40-week REACT programme, which focused on improving soccer skills and health, reported physical health benefits and other opportunities including gaining recognition through association with professional soccer clubs and community groups (Oldknow and Grant, 2008). McElroy et al (2008) evaluated the impact of a soccer programme and reported that participants' physical and mental health improved, as did confidence.

However, these studies provide little explanation about why participants, especially young people with early psychosis who are with a tertiary mental health service, might choose to participate in activity-based treatments, such as soccer programmes.

The Street Soccer programme is a once-weekly group programme that is run in a local community park. The group session is open to all young people living on the Gold Coast but is targeted towards young people experiencing difficulties such as homelessness, mental illness or drug and alcohol issues. Average weekly attendance at the street soccer programme includes 15-30 young people, including between 6-12 young people diagnosed with early psychosis. The Street Soccer programme is run by a local youth agency. The sessions are facilitated by a local volunteer soccer coach in a public, community park. Each session commences with a light physical fitness and soccer skills session followed by a social game. The group runs for approximately 1.5 hours once a week and aims to engage disadvantaged youth in a physical activity within a supportive social environment.

\section{METHOD}

\section{Research design}

An exploratory, qualitative methodology was identified to answer the research question 'why are people choosing to attend, and continue to attend, the Street Soccer programme?'. Carless and Sparkes (2008) demonstrated that a qualitative methodology can successfully uncover perspectives on physical activity engagement. A full research proposal was reviewed and provided ethical clearance by the Gold Coast Health Service District Ethics Committee prior to the project's commencement.

\section{Participants and recruitment}

This study focused on a convenience sample of participants who were regular attendees of the group. Eight regular attendees of the Street Soccer programme received information on the research project and six participants consented to participate. All were male and 18-23 years old. Participants were from a diverse range of cultural backgrounds, including three from Australia, and one each from Switzerland, Zimbabwe and New Zealand. All participants, except the participant from New Zealand, had completed their schooling in Australia. Four participants had a diagnosis of paranoid schizophrenia, one psychosis not otherwise specified and one bipolar affective disorder.

Five of the six participants had previous experience of participating in organised sporting activities, including rugby union, rugby league, tennis, soccer and martial arts. Three of these five participants had continued this involvement in sporting activities through to their high school years. The one participant who did not have previous involvement in sporting activities reported participating in organised group cultural activities, such as music during their school years. This participant was the only person who had continued to participate in organised team activities in the 12 months prior to experiencing an episode of psychosis.

\section{Data collection}

Data collection for the project commenced in May 2012 with data collection completed by July 2012. No incentive for participation was provided to the research participants. People who agreed to partici- 
pate in the research were provided with an information sheet, which was read aloud to them, and they were asked to sign a consent form allowing the collection and use of data related to their experience in the Street Soccer programme.

This project used one-to-one, semi-structured interviews to collect the research data. A group of people connected with the research and who had expertise in developing questions for qualitative research met and designed a semi-structured interview guide (Table 1). All interviews were conducted by the same researcher (one of the group facilitators). The interviews were all face-to-face, lasted approximately 45 minutes, and were audio taped for later transcription.

\section{Data analysis}

As this was exploratory work, thematic analysis was the method chosen. Full transcription of the interview was a necessary part of the process in conducting a thorough and rigorous analysis. Themes were coded on each transcript and compared with the themes arising from other transcripts. As this was a small data set, the data was analysed by hand using the process of thematic analysis (Seale and Barnard, 1998), which involved reading the transcripts, coding the responses, and organising codes into more general themes. As the analysis progressed, more specific themes were identified and clarified. The research topic informed these themes.

To ensure the trustworthiness of the results, the credibility, transferability, dependability and

\section{Table 1. Semi-structured interview guide}

1. What sort of sport have you played in the past?

2. How did you become involved in this activity?

3. What kind of things appeal to you about this activity?

4. Were there any things that concerned or worried you before you started playing soccer?

5. What were your expectations of joining the group?

6. What kind of things do you enjoy about the group? (prompts: activity, team work, connecting with others, the coach, getting out of the house)

7. What kind of things do you find to be difficult about the group? (prompts: getting tired, not having enough energy, worried about injury)

8. How would you benefit from further participation?

9. Would you consider joining a community based club after this program?

Table 2. Key themes from thematic analysis: reasons to attend Street Soccer

\begin{tabular}{ll|}
\hline Theme & Summary \\
\hline $\begin{array}{l}\text { Needing to be encouraged } \\
\text { to join the group }\end{array}$ & $\begin{array}{l}\text { Participants main motivation for initially attending } \\
\text { the group was the persistent encouragement by staff }\end{array}$ \\
\hline $\begin{array}{l}\text { Feeling welcomed and } \\
\text { encouraged }\end{array}$ & $\begin{array}{l}\text { Participants felt welcomed and encouraged in the } \\
\text { Street Soccer environment }\end{array}$ \\
\hline Gaining personal benefits & $\begin{array}{l}\text { Participants reported strong personal benefits from } \\
\text { ongoing attendance }\end{array}$ \\
\hline $\begin{array}{l}\text { Increased desire to } \\
\text { participate in new activities }\end{array}$ & $\begin{array}{l}\text { As a result of attending, participants reported a } \\
\text { desire to join other community activities }\end{array}$ \\
\hline
\end{tabular}

confirmability of the results were considered (Holloway and Wheeler, 1996). The data's credibility was considered by recruiting a Street Soccer programme group facilitator to collect the data and seeking clarification of the transcribed interviews' accuracy. During the analysis, themes were also shared between the authors, checked against other available data sources, validated with study participants and an audit trail of the work left to address dependability and confirmability.

\section{RESULTS}

Data analysis revealed four main themes (Table 2).

\section{Needing to be encouraged to join}

Participants reported the need to be persistently encouraged to join the group as the key motivating factor for them deciding to attend. All participants identified the occupational therapist working with the team as the person who motivated them to join the group, for example (NB: numbers in brackets indicate which participant is quoted):

\section{'I got involved with Street Soccer through [occupational therapist]... who has been assisting me. He encourage me to go...' (3)}

During the analysis, it was noted that the participants singled out the occupational therapist:

'[Case Manager] let me know that there was a soccer group. At first I thought I'm not a massive sports person and I might give it a skip...I spoke to [occupational therapist], I heard it again from him and I decided I may as well go along.' (5)

Surprisingly, participants did not discuss their personal or recovery goals as a reason for attending the Street Soccer programme:

\section{'At first... I was very hesitant and I wasn't expecting to get too much out of it. I thought ... I'm going to hate it.' (5) 'I didn't think that I would get anything out of it...' (1)}

\section{Feeling welcomed and encouraged}

The thematic analysis made it clear that a relaxed, welcoming and fun environment was important. All participants discussed the facilitators' (health workers and football coach) interaction style as the key factor in establishing a welcoming atmosphere

'Mainly because it's just got a real lighthearted feel to it and it's just fun to be able 
to kick a ball around and not have that sort of pressure of a real game.' (3)

'He [the coach] is very welcoming and open to who you are.' (4)

'I've noticed when you're there [health worker], you are always encouraging everyone, telling us "good play" or "good shot" or "go for it", or whatever. That sort of thing. It encourages you...' (5)

\section{Gaining personal benefits}

During the process of thematic analysis it was noted that participants' description of their motivation for attending the group changed as they attended more regularly. Participants clearly expressed personal benefits to their mental and physical health that resulted from their attendance, in contrast to their initial decision to attend:

\section{'Now, every time I go in there I expect something positive out of it and it happens every time. That's what keeps me going.' (6)}

While there was some overlap, no unifying themes emerged regarding the personal benefits participants reported. Each participant reported highly personalised benefits, which included: Three of the six participants identified they enjoyed 'getting outside the house' and 'participating in a normal activity' as reasons for enjoying the group programme. Getting out of the house held different meanings for different people. One participant identified being able to join an activity in an outdoor environment as important, whereas two others identified that getting out of the house and focussing on an activity distracted them from ongoing positive symptoms and negative thinking:

'Mainly what I enjoy is getting out of the house, being out in the sun, being out in the outdoors. I don't really do that too often nowadays, compared to what I used to.' (3) 'It's a positive cycle, so, once you get out you'll just keep going out and out. It becomes addictive... It stops you from over-thinking.' (2)

Four of the participants identified feeling more physically healthy and 'getting fit' as a main reason the group appealed to them.

'The first time I went there I got puffed out in 5 minutes. It was pretty brutal trying to run around and I'm wheezing for breath and I'm a smoker as well so it really wasn't a good combo. But now I've actually noticed that l've gotten a bit fitter...' (1)
All participants reported feeling anxious and nervous about attending the group initially. For four participants reported aspects of being worried that they wouldn't be good enough to participate or that fellow participants would judge them.

One participant identified being concerned they wouldn't be able to sustain enough motivation to commit to the programme on a weekly basis. Another participant was concerned they would be viewed negatively because they had been in hospital. One participant was concerned they might get a physical injury and another that they might not be able to get to the group. Despite these concerns, participants felt that by attending the group they experienced an increase in their overall confidence and ability:

\section{'It has helped me get out of my nervousness. Sort of out of my shell.' (2) 'I believe it starts giving that confidence to interact with people more.' (5)}

Interestingly, two participants identified the importance of the activity being structured, where they felt they knew the rules of the group (soccer rules), which helped them to engage:

\section{'It's quite easy to socialise in that sort of setting, whereas if it was everyone just hanging around... it's a bit trickier to get to know people whereas if it's a soccer game, everyone knows it's a soccer game.' (3)}

\section{Desire to participate in new activities}

All six participants identified that they felt they would be more likely to join another communitybased group as a result of attending the Street Soccer programme. However, only one participant had actually joined another programme. Four participants sought extra information from the interviewer about what other available group programmes. One participant linked participation in the group programme with increasing his motivation to engage in a vocational pursuit.

$$
\begin{aligned}
& \text { ‘Definitely give it a go [join a community } \\
& \text { group]... I've found I've started enjoying it } \\
& \text { on a consistent basis so I don't see why I } \\
& \text { wouldn't give something else a go' (2) } \\
& \text { 'It started off with just the soccer, whereas } \\
& \text { now I'm getting back into the activities I } \\
& \text { used to be involved in.' (6) }
\end{aligned}
$$

The one participant who had engaged in another group programme returned to a formal music group, renewing membership existing prior to experiencing psychosis. 


\section{DISCUSSION}

Participants initially attended the Street Soccer group as a result of the sustained and enthusiastic encouragement from staff and not because they believed they would personally benefit from the sessions. This motivational dynamic seems at odds with the current 'care planning' approach used in many modern mental health-care systems - a collaborative approach to establishing treatment goals between the consumer and the health professional (Goodwin and Lawton-Smith, 2010).

All six participants in this project had completed a similar care planning process with their case manager prior to attending the Street Soccer programme. Surprisingly, it appears this collaborative process had little, to no, impact on participants' initial decision to attend the group. For the six participants involved in this project, the key factor in deciding whether to attend the group was the health service staff's (particularly the occupational therapist's) persistent encouragement.

Biddle and Mutrie (2001) concluded that intrinsic motivation is key to sustaining exercise involvement. This certainly seems to be the case for this project's six participants. Once they had attended the group, all six participants clearly identified a range of tangible benefits beyond simply enjoying the activity that helped them feel they were moving forward in their recovery. They were also able to link recovery with their decision to continue attending the group. While participants expressed some similar themes around fitness and increasing social confidence, the diverse range of factors analysed were individual to each person. Participants in this project appeared to first have to take part in the activity before being able to link perceived tangible benefits to participation.

A common theme among all participants was the importance of the Street Soccer programme's positive social environment. All participants commented on the effect the relaxed, encouraging and friendly environment had on them. As participants did not initially attend the group with a preconceived goal, participants identified feeling welcomed and encouraged in the group environment as a key factor in deciding to continue.

In Australia, soccer is not one of the dominant professional sports; however, it is commonly played at the amateur level and is well known. Two reviews, Carter-Morris and Faulkner (2003) and McElroy et al (2008), analysed the impact of a soccer-based programme on mental health and both discuss the value of the activity itself in providing a normalising environment for participants. The results from this study support these reviews' findings, with participants reporting that the activ- ity itself was a positive factor in helping participants engage with the group. Several participants discussed feeling at ease socialising in this setting where the focus was on participating in the well-known activity of soccer and not purely on social interaction. Spandler and McKeown (2012) elucidated the potential for using soccer in health as a vehicle to engage men who are reluctant or unwilling to access services. Participants in this study clearly identified a decrease in their perceived anxiety at participating in the group due to feeling aware of the social expectations of soccer rather than an innate love of the sport. The authors, therefore, feel it reasonable to expect other culturally-appropriate sports to work in a similar fashion.

Despite these six participants entering the group with limited or no clear expectations of their objectives for attending, they continued doing so due to tangible benefits for their own recovery journey:

\section{'Especially when you've gone through a certain experience like I have [psychosis], it kind of shakes everything. It's nice to get that and go, alright, I'm going to do this [soccer], I'm going to do this and get on with things and start to improve my life rather than ... dwelling, and going... I've had this happen to me, everything's screwed. Participating in social activities really does help that, drive that a bit more.' (3)}

\section{Considerations for practice and research}

From this research, the authors identified a number of considerations for practice when working with young people living with psychosis (Table 3). The authors feel further research is warranted in three key areas. First, each of the individual group facilitators had a strong passion for sport. Due to the facilitators' significant influence on participants' attendance and enjoyment of the group, the facilitator's experiences of the group and potential correlations of this with the consumer's experience warrants further investigation.

Second, this study used a convenience sample of young people participating in the Street Soccer group at the time of data collection. However, none of the study participants were female. Further qualitative investigation should explore young womens' perception of participating in soccer programmes to understand how their experiences compare to that of young males.

Third, it is surprising that more participants were not able to make the step from the Street Soccer programme to a mainstream community group despite wishing to do so. However, considering how participants engaged with the Street Soccer programme, it seems likely a similar process of per- 
sistent encouragement by someone they know may assist young people to move from a therapy group to a mainstream activity. Further qualitative analysis to understand the particular barriers and motivators faced by young people with psychosis seeking to move from a group therapy programme to mainstream community groups could be beneficial.

\section{Limitations}

This study has a number of limitations. The person who completed the study's data collection was also a group facilitator who was passionate about the soccer group. While this enabled the interviewer to engage with the participants about their experiences, it also had the potential to result in interviewer bias towards the group's more positive aspects. This study used a convenience sample of people who had chosen to regularly attend the Street Soccer programme and was limited to investigating the experiences of the young people who regularly participated. While this allowed exploration of attendees' experiences, it fails to consider the experiences of people who discontinued.The findings are not designed to be representative of all young people with early psychosis, but rather to analyse the experiences of people who participated in this study for others to consider during care planning or future research.

\section{CONCLUSION}

This study explored the experiences of young people who participated in a Street Soccer programme and aimed to gain a greater understanding of why they chose to attend and continue participating in the group. Thematic analysis of the data revealed that the participants initially decided to attend the Street Soccer group as a result of appropriate, persistent encouragement from staff. Despite active conversations about their recovery goals, the majority of participants did not enter the group programme with a clear expectation of what they wanted to achieve by attending the group. However, once engaged, participants continued to attend the group programme because they enjoyed it and, more importantly, because they felt some personal benefit from attending. IJTR

Biddle SH, Mutrie N (2001) Psychology of physical activity. Determinants, well-being and interventions. In: Creek J, Lougher L (2008) Occupational Therapy And Mental Health. 4th edn. Elsevier, PA: 288

Carless D, Douglas K (2004) A golf programme for people with severe and enduring mental health problems. J Ment Health Promotion 3(4): 26-39

Carless D (2007) Phases in physical activity initiation and maintenance among men with serious mental illness. Int J Ment Health Promotion 9(2): 17-27

Carless D, Douglas K (2008) Social support for and through exercise and sports in a sample of men with serious mental illness. Issues Ment Health Nurs 29(11): 1179-99
Table 3. Recommendations for practice with young people with psychosis

Engaging young people in group programs: Participants benefit from appropriate, persistent encouragement to engage in a suitable group program

Developing a care plan: Identify and negotiate individual goals for attending a therapy programme (care plan) after participants have attended a number of times to allow participants time to identify benefits from participation.

Type of activity: When developing open groups for youth, consider the type of activity the group is based around, e.g. soccer is a non-threatening, normalising activity.

Transferring from a therapy based group to a mainstream community group: Provide ongoing support to those who wish to move into mainstream community groups.

Carless D, Sparkes A (2008) The physical activity experiences of men with serious mental illness: three short stories. Psychol Sport Exercise 9(2): 191-210

Carter-Morris P, Faulkner G (2003) A football project for service users: The role of football in reducing social exclusion. J Ment Health Promotion 2(1): 24-30

Crone D (2007) Walking back to health: A qualitative investigation into service users' experiences of a walking project. Issues Ment Health Nurs 28(2): 167-83

Daumit GL, Goldberg RW, Anthony C, Dickerson F, Brown CH, Kreyenbuhl J et al (2005) Physical activity patterns in adults with severe mental illness. J Nerv Ment Dis 193(10): 641-6

Ellis N, Crone D, Davey R, Grogan S (2007) Exercise interventions as an adjunct therapy for psychosis: A critical review. $\mathrm{Br}$ $J$ Clin Psychol 46(1): 95-111

Goodwin, N and Lawton-Smith, S (2010). Integrating care for people with mental illness: the care programme approach in England and its implications for long-term conditions management. Int J Integrated Care 10(1)

Hodgson MH, McCulloch HP, Fox KR (2011) The experience of people with severe and enduring mental illness engaged in a physical activity programme integrated into the mental health service. Ment Health Phys Activity 4(1): 23-9

Holloway I, Wheeler S (1996) Qualitative research for nurses. Blackwell Science, Oxford

McElroy P, Evans P, Pringle A (2008) Sick as a parrot or over the moon: An evaluation of the impact of playing regular matches in a football league on mental health service users. Prac Develop Health Care 7(1): 40-8

Oldknow H, Grant G (2008) Does joining a football academy help mental health recovery? Ment Health Nurs 28(2): 8-11

Penedo FJ, Dahn JR (2005) Exercise and well-being: A review of mental and physical health benefits associated with physical activity. Curr Opin Psychiatry 18(2): 189-93

Richardson CR, Faulkner G, McDevitt J, Skrinar GS, Hutchinson DS, Piette JD (2005) Integrating physical activity into mental health services for persons with serious mental illness. Psychiatr Serv 56(3): 324-31

Saxena S, van Ommeren M, Tang KC, Armstrong TP (2005) Mental health benefits of physical activity. J Ment Health 14(5): 445-51

Seale J, Barnard S (1998) Therapy Research. Processes And Practicalities. Butterworth-Heinemann, Oxford

Soundy A, Faulkner G, Taylor A (2007) Exploring variability and perceptions of lifestyle physical activity among individuals with severe and enduring mental health problems: A qualitative study. J Ment Health 16(4): 493-503

Spandler H, McKeown M (2012) A critical exploration of using football in health and welfare programmes: gender, masculinities, and social relations. J Sport Soc Issues 36(4): 387-409

Tessier S, Vuillemin A, Bertrais S, Boini S, Le Bihan E, Oppert JM et al (2007) Association between leisure-time physical activity and health-related quality of life changes over time. Prev Med 44(3): 202-8

\section{KEY POINTS}

- This project aimed to identify why consumers were choosing to join and continue attending a street soccer program.

- This paper indicates that group facilitators should: be aware of the importance of the therapeutic use of self (i.e. encouraging attendance) when engaging young people living with mental illness in groups and actively assist participants to reflect on their experiences of attending. 
Copyright of International Journal of Therapy \& Rehabilitation is the property of Mark Allen Publishing Ltd and its content may not be copied or emailed to multiple sites or posted to a listserv without the copyright holder's express written permission. However, users may print, download, or email articles for individual use. 